\title{
Protect and regulate China's oyster resources
}

China has at least 30 oyster species (1), all of which provide valuable ecosystem services. Oysters' filter feeding habit reduces suspended particles and nutrients. One hectare of oyster reef can clean a volume of water equivalent to nearly 15 Olympic swimming pools daily (2). Oysters' excrement can stimulate denitrification by removing nitrogenous organic matter, helping to mitigate eutrophication (3). Natural oyster reefs provide habitat for many species, enhancing biodiversity and increasing fisheries. Oyster reefs can reduce impacts of waves caused by hurricanes and typhoons, stabilizing shorelines (4). Despite their ecological importance, $85 \%$ of oyster reefs globally have been degraded since the 19th century by overharvesting, coastal development, water pollution, and disease (4). China's oyster reefs, especially those in Tianjin and Jiangsu $(5,6)$, have been seriously damaged during recent decades. Urgent action by Chinese authorities is required to protect these crucial species.

Extensive degradation of natural oyster reefs has been accompanied by rapid development of oyster aquaculture, driven by high profitability (7). China's oyster farming accounts for more than $80 \%$ of global production and covers more than $1400 \mathrm{~km}^{2}(8)$. However, fewer than $10 \%$ of oyster farmers have aquaculture licenses or permits (9). Poor water-quality management within large aquaculture developments contaminates oysters with heavy metals, organohalogens, and viruses (10). Very high concentrations of cadmium, lead, inorganic arsenic, and polychlorinated biphenyl now occur in oysters in southern China, posing carcinogenic risks (10).

China should address the threats to natural oyster reefs by providing stronger protection, ceasing inappropriate coastal development, and reducing water contamination. Effective regulation of aquaculture must include exclusion of polluted waters and stringent depuration procedures. The Restorative Aquaculture Opportunity Index should be used to identify areas for oyster aquaculture (11). Finally, China can help protect oyster reefs as well as other kinds of aquatic life by promoting sustainable prawn-fish-shellfish-algae polyculture instead of single-species aquaculture (12).

\footnotetext{
Hong Yang ${ }^{1,2,{ }^{*}}$, Mingguo Ma ${ }^{1}$, Julian R. Thompson ${ }^{3}$, Roger J. Flower ${ }^{3}$

${ }^{1}$ Chongqing Jinfo Mountain Karst Ecosystem National Observation and Research Station, School of Geographical Sciences, Southwest University, Chongqing 400715, China.

2 Department of Geography and Environmental Science, University of Reading, Reading RG6 6AB, UK.

${ }^{3}$ Department of Geography, University College London, London, WC1E 6BT, UK.

Corresponding author. Email: hongyanghy@gmail.com
}

\section{References and Notes}

1. X. M. Guo, C. Li, H. Y. Wang, Z. Xu, J. Shellfish Res. 37, 755 (2018). 
2. L. D. Coen et al., Mar. Ecol. Prog. Ser. 341, 303 (2007).

3. M. L. Kellogg, M. J. Brush, L. Kellogg, M. Brush, “An updated model for estimating the TMDL-related benefits of oyster reef restoration" (Virginia Institute of Marine Science, 2018).

4. M. W. Beck et al., Bioscience 61, 107 (2011).

5. W. Quan et al., Acta Ecol. Sin. 36, 7749 (2016).

6. W. Sun et al., Hebei Fishery 249, 23 (2014).

7. J. A. Fitzsimons et al., Conserv. Sci. Pract. 2, 10.1111/csp2.198 (2020).

8. Fishery Bureau of the Ministry of Agriculture of the People's Republic of China, "China fishery statistical yearbook 2019" (China Agriculture Press, 2020) [in Chinese].

9. H. Li et al., Mar. Sci. 41, 125 (2017).

10. H. Liu et al., J. Shanghai Ocean Univ. 26, 921 (2017).

11. S. J. Theuerkauf et al., PLOS One 14, 10.1371/journal.pone.0222282 (2019).

12. D. C. Little et al. Aquaculture 493, 338 (2018). 